\title{
Pendekatan Behavior Setting pada Penataan Lingkungan Kampung Akuarium dalam Desain Rumah Susun
}

\author{
Dhisa Yustiara dan Rullan Nirwansyah \\ Departemen Arsitektur, Fakultas Arsitektur, Desain, dan Perencanaan, Institut Teknologi Sepuluh Nopember (ITS) \\ e-mail: rullan@arch.its.ac.id
}

\begin{abstract}
Abstrak-Behaviour Setting atau pola perilaku adalah sistem sosial berskala kecil, dibatasi oleh waktu dan tempat, terdiri dari users dan benda - benda fisik dimana ruang dan waktu sebagai batas identifikasi pola perilaku dan user dan objek merupakan komponen utama karena user-lah yang membuat perilaku itu ada. Perubahan lingkungan yang terjadi pada kondisi fisik yang baru merupakan salah satu persoalan yang harus diselesaikan, lingkungan baru berarti kebiasaan baru juga. Mendengar kata perilaku menunjuk pada manusia dengan aksinya, aktivitas secara fisik, berupa interaksi antar sesama manusia ataupun dengan lingkungan fisiknya. Lingkungan rumah susun akan menjadi hal yang berbeda dan perlu diperhatikan sebagai pembandingnya dengan lingkungan kampung yang terbiasa dengan kondisi rumah tapak. Konteks rumah susun disini walau secara bentuk akan berbeda tetapi bagaimana perilaku warga kampung Akuarium tetap sama. Lingkungan sama tetapi objek huniannya berbeda.
\end{abstract}

Kata Kunci-Aktivitas, Behavior Setting, Lingkungan, Perilaku Manusia, Rumah Susun.

\section{PENDAHULUAN}

$\mathbf{J}^{\prime}$ AKARTA adalah ibu kota Indonesia, kota ini memiliki banyak permasalahan perkotaan, salah satunya adalah permasalahan permukiman penduduk di kampung. Jakarta memiliki banyak perkampungan dari kampung yang sudah ada dari jaman kolonial belanda, kampung di pinggiran bantaran kali, hingga kampung yang tercipta karena kumpulan hunian tak bersertifikat. Selama 2 tahun (2014-2016) sudah sebanyak 12 kampung yang telah tergusur di Jakarta.

Kampung-kampung tersebut digusur berdasarkan berbagai macam masalah yang ditimbulkan, dari penyebab banjir hingga karena hunian liar. Kampung yang tergusur kemudian di relokasi ke berbagai tempat dan di tempatkan di sebuah rumah susun (berbasis sewa). Rumah susun merupakan sebuah pemecahan solusi untuk mengurangi kepadatan penduduk di kota yang lahannya semakin terbatas akibat banyaknya pendatang dari desa ke kota. Rumah susun juga merupakan solusi yang diberikan oleh pemerintah utnuk mengurangi hunian liar yang ada di kota.

Permasalahan yang terjadi ketika relokasi dilakukan adalah perubahan kondisi lingkungan sekitarnya yang dapat berdampak pada kegiatan sosial-ekonomi dari warga. Masalah tersebut muncul di kampung pesisir pantai, masyarakat yang terbiasa bergantung hidup dengan laut akan terganggu kehidupan sosial-ekonominya karena sebagian besar

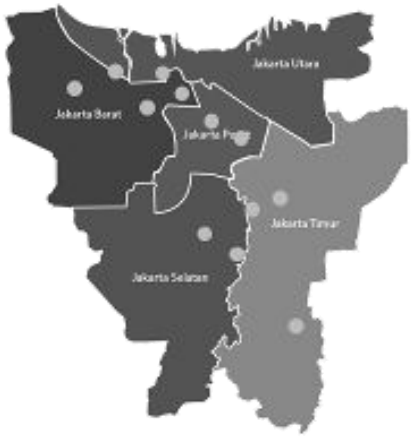

Gambar 1. Peta lokasi penggusuran kampung-kampung di Jakarta dari tahun 2014 hingga tahun 2016.

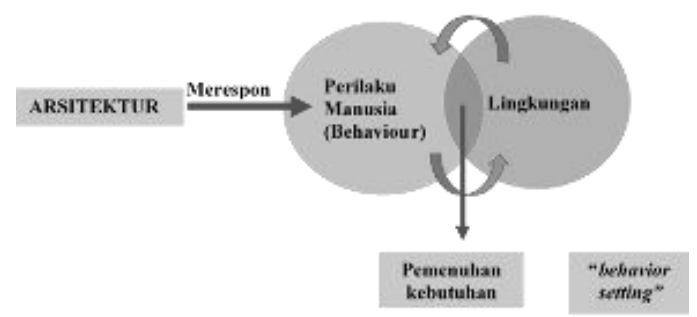

Gambar 2. Behavior Setting dalam arsitektur menurut Joyce M. Laurens dimana arsitektur merespon behavior yang saling memilki timbal balik dengan lingkungan untuk pemenuhan kebutuhan.

penghasilan berasal dari hasil laut. Ketika mereka berada jauh dari laut maka mereka perlu beradaptasi terhadap lingkungan barunya yang tidak ada laut ataupun perahu, dan tentunya perilaku mereka akan berubah mengikuti kondisi lingkungan terkini.

\section{A. Isu dan Konteks Desain}

Setiap arsitektur yang dibuat atas dasar kebutuhan manusia menghasilkan efek perilaku yang berbeda terhadap arsitektur itu sendiri. Mengenai pembangunan kembali arsitektur yang diadaptasi dari kebutuhan dan perilaku manusia yang berdampak terhadap psikologi seseorang.

Dalam buku Arsitektur dari segi Perilaku oleh Clovis Heimsath, dijelaskan bahwa Arsitektur, menurut pengertiannya, adalah dibangun untuk manusia [1]. Kualitas lingkungan dapat mempunyai dampak luas terhadap perilaku dan kepribadian individu. Lingkungan berperan sebagai pembentuk kekuatan motivasi pada manusia (proses afektif dan attitudinal serta adaptasi). Hubungan manusia dan lingkungan bersifat integral dan timbal balik [2]. 


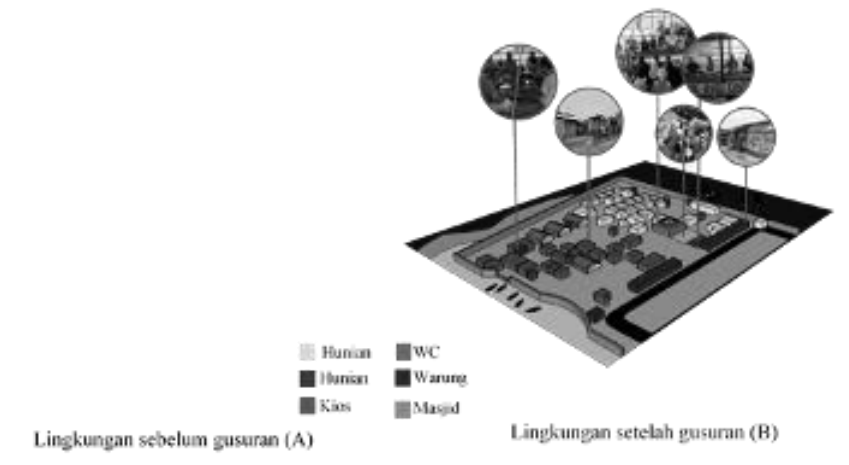

Gambar 3. Perbandingan kondisi lingkunga, perilaku, dan aktivitas Kampung Akuarium sebelum (>2016) dan sesudah digusur (2016-sekarang).

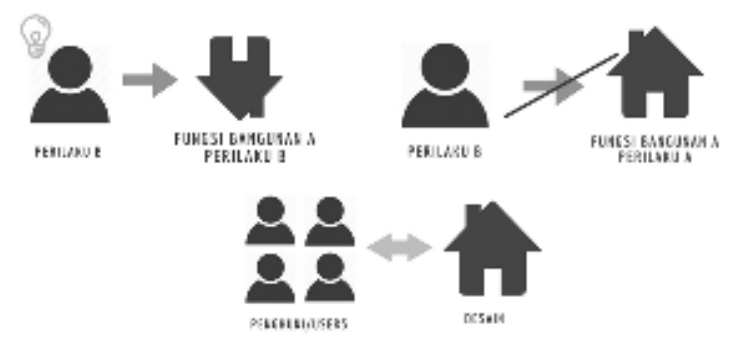

Gambar 4. Timbal balik Penghuni dengan objek desain dimana harus saling terikat agar tidak terjadi miss-conception terhadap objek yang didesain.

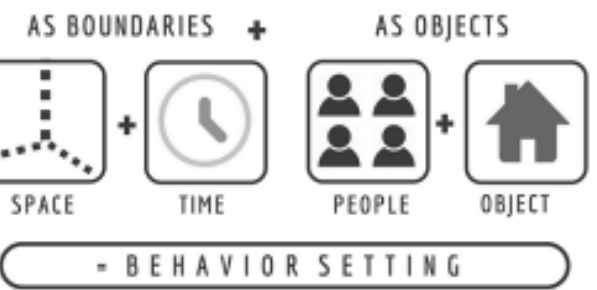

Gambar 5. Behavior Setting menurut Teori dari Wicker dan Baerker yang dilihat dari batas waktu dan tempat serta objek dan people/user sebagai objeknya.

Mendengar kata perilaku menunjuk pada manusia dengan aksinya, aktivitas secara fisik, berupa interaksi antar sesama manusia ataupun dengan lingkungan fisiknya. Perilaku manusia dibagi menjadi dua jenis yaitu nature perilaku yang sudah ada di dalam diri manusia itu sendirimelalui naluri genetika, dan nurture yaitu perilaku yang terbentuk berdasarkan lingkungan fisiknya bisa melalui pengalaman maupun pelatihan [3]. Perilaku seseorang ada pengaruhnya juga terhadap budaya dan faktor pengaruh lingkungan yang saling terkait satu sama lain.

Perilaku manusia dengan lingkungannya baiknya ada timbal balik, saling terkait, dan saling mempengaruhi, dan memerhatikan sebab dan akibatnya dalam merespon arsitektur [4]. Pemahaman yang terbagi dua yaitu bagaimana perilaku manusia membentuk Arsitektur dan bagaimana Arsitektur membentuk perilaku manusia dapat dijelaskan terbentuknya ruang dalam yang didasari dari perilaku manusia serta berfungsi dengan benar sebagaimana mestinya sebagaimana yang diinginkan/ diharapkan oleh manusia sebagai pengguna [4].

Menurut Winston Churchill, manusia yang membentuk bangunannya kemudian bangunan itu yang akan membentuk kita (manusia). Manusia membangun bangunan demi

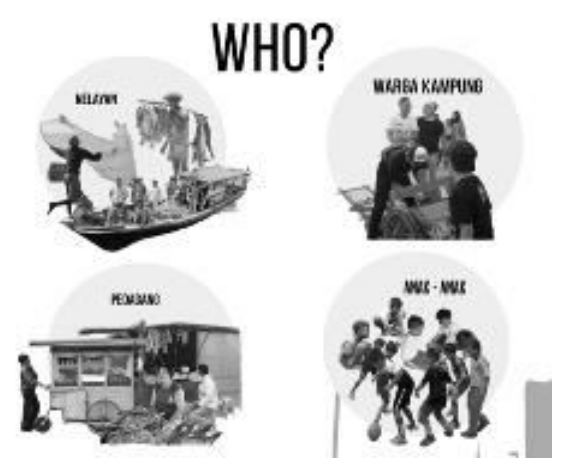

Gambar 5. Subjek pada Kampung Akuarium yang menjadi penghuni.

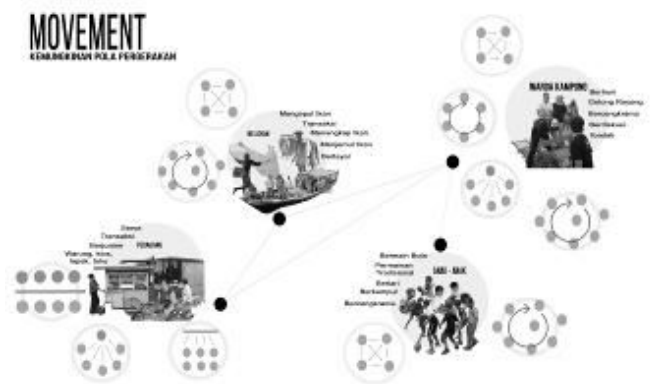

Gambar 6. Pola perilaku yang terjadi pada subjek di Kampung Akuarium.

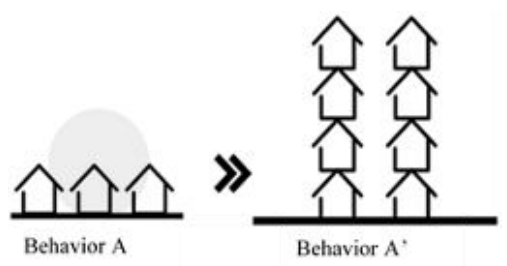

Gambar 7. Objek perilaku dimana perilaku landed house tidak akan sepenuhnya dibawa ke rumah susun akibat perbedaan jenis bentuk hunian Penataan Lingkungan.

pemenuhan kebutuhannya sendiri, kemudian bangunan itu membentuk perilaku manusia yang hidup dalam bangunan tersebut. Bangunan yang didesain oleh manusia yang pada awalnya dibangun untuk pemenuhan kebutuhan manusia tersebut mempengaruhi cara manusia itu dalam menjalani kehidupan sosial dan nilai-nilai yang ada dalam hidup, dalam bahasan disini dapat dilihat dari bagaimana terbentuknya ruang yang didasari oleh perilaku seseorang atau beberapa orang.

Pola perilaku terjadi pada pertemuan antara individu dengan lingkungannya terdapat arus timbal balik antara penghuni dengan desain yang disampaikan sehingga penghuni/users merasa sesuai dengan perilakunya. Hubungan timbal balik inilah yang menjadi isu utama dari desain rumah susun dan interaksinya terhadap ruang luar [3].

\section{B. Usulan Objek Desain}

Kondisi Kampung Akuarium yang dahulu terlihat kumuh dan dengan lingkungan yang kurang sehat maka solusi yang ditawarkan adalah pembangunan rumah susun di wilayah Kampung Akuarium sebagai kebutuhan hunian yang layak tetapi dengan melihat perilaku masyarakat kampung yang dulu sebagai acauan dan tolak ukur dalam mendesain rumah susun nantinya. Tolak ukur perilaku warga Kampung Akuarium 


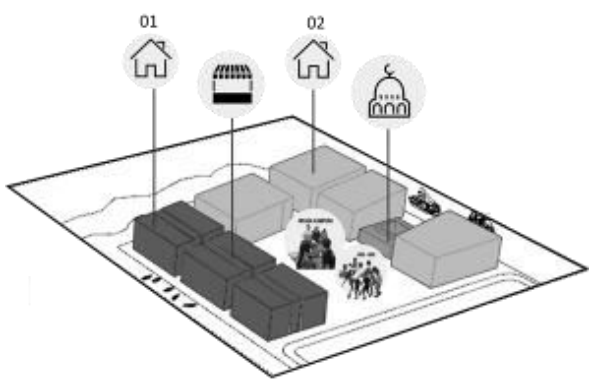

Gambar 9. Penambahan pasar dan ruang luar sebagai pemenuhan interaksi hunian dan penghuni.

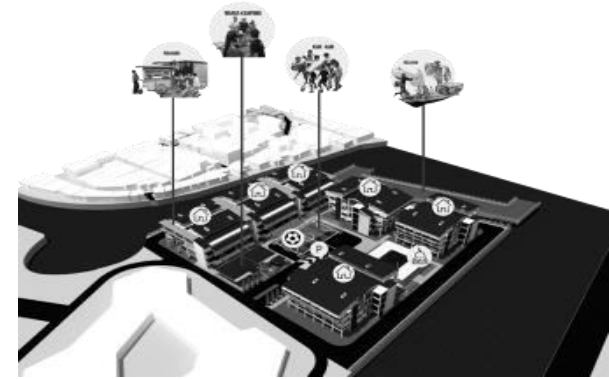

Gambar 10. Hasil desain penataan lingkungan rumah susun di Kampung Akuarium.
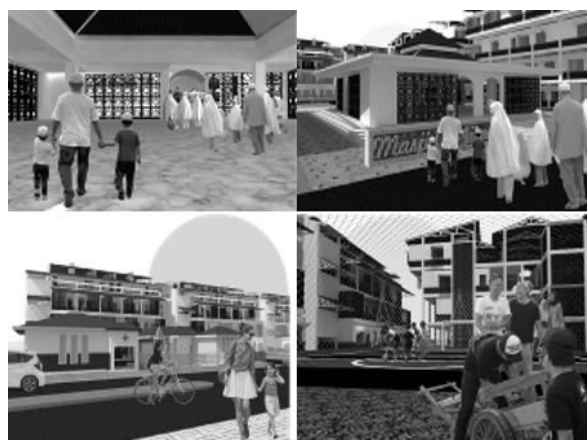

Gambar 11. Fasilitas pendukung rusun dan suasana lingkungan.

ditambahkan karena warga ingin mengembalikan kampungnya yang dahulu dan dapat melakukan aktivitas warga kampung sebagaimana mestinya.

Lingkungan rumah susun akan menjadi hal yang berbeda dan perlu dilihat untuk membedakan lingkungan kampung yang memiliki rumah dan lahan sendiri. Konteks rumah susun disini walau secara bentuk akan berbeda tetapi bagaimana perilaku warga kampung Akuarium tetap sama. Hal tersebutlah yang menjadi bahasan pokok dalam mendesain rumah susun dan interaksinya dengan ruang terbuka sebagai pemenuhan behavior warga Kampung Akuarium.

\section{METODE PERANCANGAN}

Behavior setting adalah sistem sosial berskala kecil, dibatasi oleh waktu dan tempat, terdiri dari users dan benda - benda fisik dimana ruang dan waktu sebagai batas identifikasi pola perilaku dan user dan objek merupakan komponen utama karena user-lah yang membuat perilaku itu ada [4]. Kendati demikian, interaksi user dengan objek menentukan apa itu behavior setting [5].

Behavior Mapping merupakan sebuah metode yang dapat

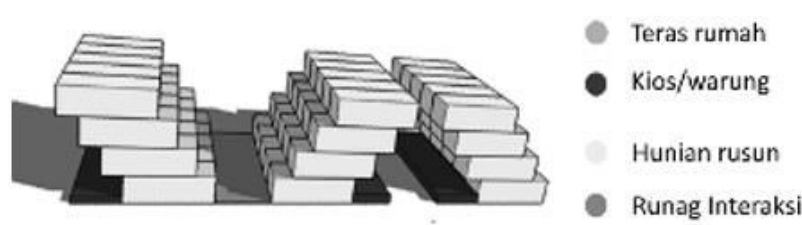

Gambar12. Program ruang pada desain rusun.
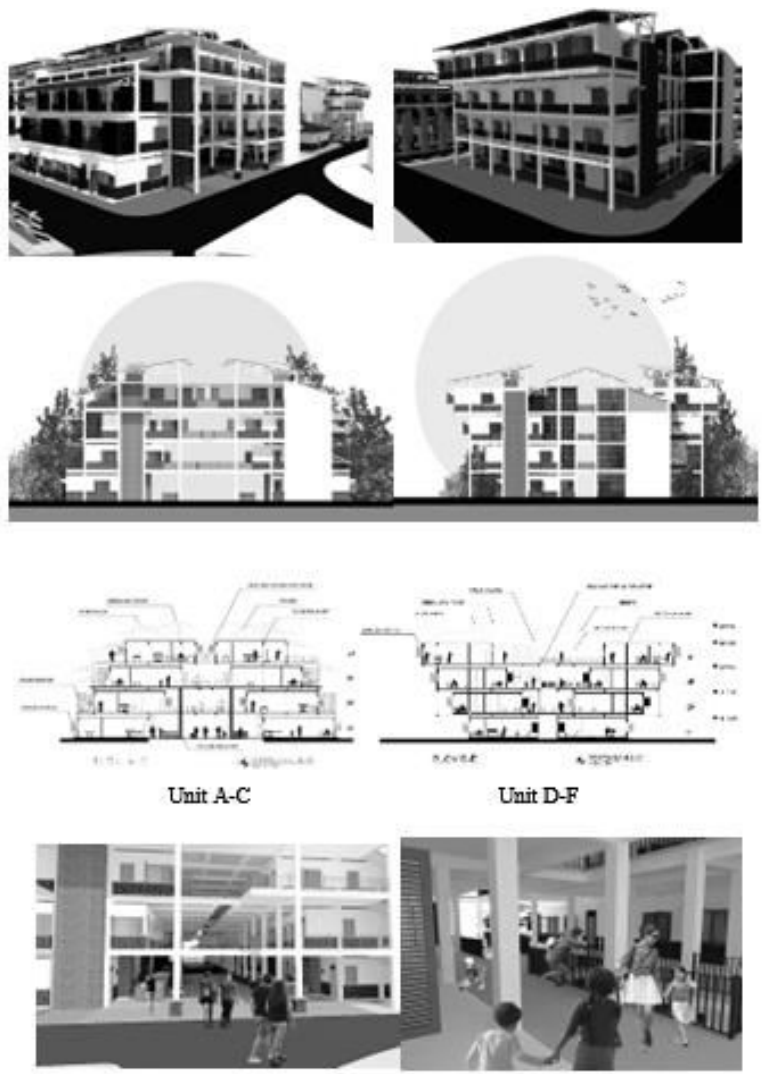

Gambar13. Detail Desain Rumah susun.

dilakukan dengan adanya pendekatan behavior setting. Langkah awal yang harus dilakukan adalah melihat siapa subjeknya (dalam konteks ini subjek merupakan people/user) dalam suatu media (objek), serta dimana subjek dan objek itu berada (lingkungan) dan kapan subjek objek itu bergerak dan ada pada lingkungan.

Menurut Ittelson, pemetaan perilaku, secara umum akan mengikuti prosedur yang terdiri dari 5 (lima) unsur dasar, yaitu: [6][7].

1. Sketsa dasar area atau seting yang akan diobservasi.

2. Definisi yang jelas tentang bentuk-bentuk perilaku yang akan diamati, dihitung, dideskripsikan dan didiagramkan.

3. Infomasikan satu rencana waktu yang jelas pada saat kapan pengamatan akan dilakukan.

4. Prosedur sistematis yang jelas harus diikuti selama observasi.

5. Sistem coding/penandaan yang efisien untuk lebih mengefisienkan pekerjaan obsevasi [6][7].

Mapping perilaku tersebut akan menunjukan bagaimana nantinya merespon sebuah rancangan tipologi rumah susun 
dengan ruang terbukanya agar sesuai dengan perlaku penghuninya dengan melihat dari sebuah site kemudian memberi tanda dimana dan apa perilaku yang terjadi.

\section{EKSPLORASI HASIL}

Perilaku berhuni dari yang semula berupa landed house (rumah tapak) akan berbeda dengan perilaku berhuni berupa vertical house atau yang biasa sering terlihat berupa rumah susun.

Bentuk hunian ada dua jenis yaitu landed house dan vertical house, dua jenis ini memiliki perilaku penghuni yang berbeda pula. Rumah susun yang didesain menginvers perilaku dari landed house ke vertical house, hal tersebut dilakukan untuk mencoba tidak merubah perilaku warga kampung Akuarium yang dulu, akan tetapi perilaku tersebut tidak akan dapat sama seutuhnya karena objeknya telah berubah

Perilaku pada landed house diumpamakan sebagai "Behavior A" dan perilaku pada vertical house diumpamakan dengan "Behavior A"' yang artinya bahwa perilaku dalam landed house tidak akan sepenuhnya sama persis bila di perilaku tersebut dimasukan ke dalam vertical house.

Desain lingkungan pada rumah susun melihat dari peletakan massa dari kondisi lingkungan Kampung Akuarium mulai dari kondisi sebelum digusur dan setelah digusur dengan pertimbangan dari hasil behavior mapping. Pertama dimulai dari penataan massa bangunan rusun kemudian membentuk ruang luar dengan pertimbangan tidak merubah letaknya.

Gambar 8 merupakan hasil adaptasi dari kondisi Lingkungan Kampung Akuarium yang posisinya tidak berubah, dengan keterangan sebagai berikut:

1. Meletakan massa hunian (rumah susun) dengan melihat kondisi lingkungan dari letak hunian di Kampung Akuarium

2. Membagi massa hunian (rumah susun) menjadi beberapa massa agar tidak terkesan terlalu masif.

3. Menambah satu ruang kosong untuk diletakan fasilitas pendukung lain. Berbentuk " $U$ " dengan orientasi mengarah ke selatan atau jalan utama.

4. Meletakan masjid di lokasi eksisting pada Kampung Akuarium

Penataan dari Lingkungan dan desain rumah susun Kampung Akuarium berupa adaptasi lanjutan dari lingkungan eksisting Kampung Akuarium. Terdapat beberapa perubahan dan penambahan dimana eksisting tidak memiliki ruang luar menjadi memiliki ruang luar sehingga kebutuhan perilaku yang terjadi pada saat setelah digusur dimana warga lebih sering menghabiskan waktunya diluar hunian dapat terpenuhi.

Pendekatan Behavior Setting yang menghasilkan tatanan lingkungan kemudain diolah menjadi bentuk siteplan yang utuh berdasarkan mapping yang telah dilakukan pada metode desain.

Seperti pada pola lingkungan Kampung Akuarium yang sebelum dan sudah digusur letak masjid tetap pada posisi eksisting dengan memperbesar ukuran masjid agar lebih banyak menampung warga serta aktivitas lain yang terjadi didalamnya seperti berdiskusi dan rapat bisa tercakupi dengan maksimal. Kemudian ditambahkan lapangan dengan ukuran yang sesuai agar mencakup kegiatan eventual yang biasa dilakukan warga setelah huniannya digusur. Selain itu terdapat fasilitas umum lain yang dimana fasum tersebut telah ada sebelum digusur yaitu Puskesmas-Posyandu dan Taman Kanak - Kanak.

Pada rusun blok $\mathrm{A}, \mathrm{B}$, dan $\mathrm{C}$ terdapat pasar pada lantai dasar. Bentuk massa yang menerupai tangga menghasilkan lahan sisa yang dapat dimanfaatkan untuk meletakan kios kios yang dulu ada sebelum kampung ini digusur agar memunculkan kembali kios-kios yang hilang akibat Kampung Akuarium digusur.

Berbeda dengan blok A, B, dan C, Blok D, E, dan F tidak difungsikan lagi sebagai pasar melainkan sepenuhnya hunian. Bentuk Massa dari Blok D, E, dan F berbentuk tangga terbalik agar lahan yang tersisa dapat dimanfaatkan sebagai fasilitas ruang terbuka pada hunian dan karena bentuknya yang semakin melebar tiap lantai atas mengakibatkan selasar dalam rusunmenjadilebih luas sehingga penghuni/users tidak merasakan hunian yang sempit dan perilaku interaksi dapat berjalan dengan maksimal dan pergerakan lebih leluasa.

\section{KESIMPULAN}

Sebuah hunian dan lingkungannya bila didesain dengan tidak melihat perilaku penghuninya dapat memungkinkan terjadinya kesalapahaman fungsi dari desain yang akan disampaikan, Karena arsitektur dibangun untuk manusia.

Desain lingkungan pada rumah susun melihat dari peletakan massa dari kondisi lingkungan Kampung Akuarium mulai dari kondisi sebelum digusur dan setelah digusur dengan pertimbangan dari hasil behavior mapping. Pertama dimulai dari penataan massa bangunan rusun kemudian membentuk ruang luar dengan pertimbangan tidak merubah letaknya. Pendekatan Behavior Setting yang menghasilkan tatanan lingkungan kemudain diolah menjadi bentuk siteplan yang utuh berdasarkan mapping yang telah dilakukan pada metode desain.

\section{DAFTAR PUSTAKA}

[1] C. Heimsath, "Behavioral Architecture: Design as if People Mattered," Clovis Heimsath Assoc., vol. 19, 1978.

[2] J. Lang, Creating Architectur Theory: The Role of the Behavior Sciences in Environmental Design. New York: Van Nonstrand Reinhold Company, 1987.

[3] J. M. Laurens, Arsitektur dan Perilaku Manusia. Jakarta: Grasindo, 2004.

[4] R. Barker, Ecological Psychology: Concept and Methods for Studying the Environment of Human Behaviour. California: Stanford University Press, 1968.

[5] A. Blanchard, "Virtual Behavior Settings: An Application of Behavior Setting Theories To Virtual Communities," Oxford Acad. J. Comput. Commun., vol. 9, 2017.

[6] H. Proshansky, W. H. Ittelson, and L. . Rivlin, Environmental Psychology. USA: Holt, Rinehart \& Winston, Inc, 1976.

[7] M. Riany, D. Pahmawati, M. . Yughni, and Y. Zabitha, "Pola Perilaku Anak Pada Jalur Sirkulasi Horisontal \& Vertikal Di Rusunawa Cibeureum Cimahi." 